\title{
A STUDY ON JOB PERFORMANCE AND ATTITUDE OF EMPLOYER ON THE BUSINESS ADMINISTRATION GRADUATES
}

\author{
NGUYEN VAN THANH TRUONG \\ Industrial University of Ho Chi Minh City, Vietnam \\ nguyenvanthanhtruong@iuh.edu.vn
}

\begin{abstract}
The study aimed to determine factors affect to employer's attitude of graduating from college with a degree in business administration, and support to education organisations build the learning outcomes approach to the requirement of the employer. The study conducted interviews and focus groups deal with employers. The results asserted that job performance has a substantial effect on the attitude's employers. Moreover, the construct of the job performance of graduates represented as a higher-order factor structure rather than a correlated set of first-order factors consists of reliability, knowledge, cognitive skills, social skills, technical skills. These components assessed which SMEs company will be interested in the process of recruiting.
\end{abstract}

Keywords. Job performance, employer's attitude, Job skills.

\section{INTRODUCTION}

Vietnam is in a period of developing cooperation with potential countries, the associations, and the international economic community. In such a context, Vietnamese enterprises need to improve their competitiveness, and the quality of human resources is considered to be the primary focus. Vietnam Education laden theory and for graduates, business administration students still exists a big gap between theory and practice based on the credit of theory and practice embodied in the training programs of Universities. The situation poses challenges for the university to provide human resources for economic development and society. With this approach, the quality of training is assessed through the level of training effectiveness based on the ability to meet the training needs of the trainee after completing the training program. Accurately defining the criteria for assessing the requirements and ability to meet professional is an effective way to adjust and orient higher education.

According to the Ministry of Labor [1] announced the increasing number of employed students compared to the previous quarter of 2016. However, the labour rate wage of this quarter slightly decreased compared to the previous quarter, although still higher than in the same period last year. Unemployment decreased slightly in both quantity and proportion. The rate of young unemployed decreased slightly, but unemployment of university student increased compared to quarter $2 / 2017$. From the information of the labour market, the unemployment rate of the university student is still high compared to the actual demand. Also, interviews with enterprises show that enterprises have to retrain university graduates to suit their requirement. Therefore, it is necessary to have specific policies and activities for training to meet the needs of society.

These studies are designed to understand issues related to assessing the quality of university education in the perspective of employers on employees, as an approach in the effort to improve the quality of university education. Although there are studies on the ability of students to meet requirement skills under the assessment of employers, there are few of them focus on the business administration graduates. Therefore, the study aims to clarify the concept of training quality according to the quality of "outcome" that is currently concerned, as well as the methodology to evaluate the quality of training. The research applies theory related to measuring the quality of training to measure the level of skills, reliability and knowledge of business administration students after graduation through a questionnaire survey. In order to adjust, supplement and build a scale to assess the factors of skills, knowledge and reliability of graduates who conduct an internship in business administration at enterprises, is the first target that the research. The second goal is to identify important factors affecting the attitude of employers through research results.

\section{LITERATURE REVIEWS}


Although there are few studies related to the skills, knowledge and reliability of graduates, mainly interview respondents who are alumni or lecturers, and for respondents as employers are very limited. The respondents are lecturers; alumni or employers are all proofs of indirectly evaluating the training quality of the program or courses. However, in order to have a high level of reliability in assessing and making decisions to adjust in the orientation of training, cross-checking of measurement methods and tools is required. (Table 1)

Motowildo [2] defined job performance as the total expected value to the organisation of the discrete behavioural episodes that an individual carries out over a standard period. This definition is a slightly revised version of the definition of performance presented in a previous publication in connection with a theory of individual differences in task and contextual performance. The studies of the job performance of graduates summarise mainly in two main prospectives.

First, the study by Bridges, et al. [3] based on both groups of respondents were internships and lecturers; the research team concluded given the team skills include, Media, Presentation, Conflict Resolution, Corporate Culture, Communication, Health, and Understanding of diversity of employees. Hương and Khải [4] expanded research and argue for groups necessary skills in aspects of leadership skills, interactive communication, analytical skills, ability to decide, applicability, technology, awareness of the whole Bridge, Ethics, Planning, Self-Management. Lan and Hiển [5] has inherited and expanded research into the Vietnamese environment and argued that the necessary skills for graduates to meet employer's requirement include primary skill groups, group of increasing value and the group of future leaders.

Second is the inheritance research developed from the foundation theory and selected research subjects as employers [6]. The objects as employers provided a summarised group of necessary skills for students including critical thinking, ability to work professionally, communication skills, awareness of multinational culture, the ability to apply technology, proficient of the field. They are inheriting research, Lê and Đỗ [7] survey study on employers and results with factors of ability to solve casework, ability to meet jobs. Recently adaptable Lan and Hiển [5] research on the assessment of the employer regarding quality university training for group engineering - technology, and the result indicated that the quality assessment must be based on the concern of the employer. One of the most critical factors for businesses is the quality of "output", precisely the capacity and qualifications of graduates. The study results showed that technical, cognitive, and social and behavioural skills. Technical skills reflect the competencies related to the expertise of a particular profession, including theoretical knowledge, practice and skills related to the expertise of a specific profession. Cognitive skills reflect the ability to solve problems instinctively compared the use of knowledge to solve problems. Social skills and behaviour (Social and Behavioral skills) reflect social relationships, soft skills, character traits.

Thus, depending on the situation and characteristics of survey groups will deliver different results and a change in the skill group. The above studies show that Job performance is conceptual of multicomponent structure and adjusted according to the target group.

Table 1. Summary of related studies

\begin{tabular}{|c|l|l|}
\hline Author & $\begin{array}{c}\text { Objects } \\
\text { of survey }\end{array}$ & \multicolumn{1}{|c|}{ The skills are summarised } \\
\hline Huong and Khai [8] & Student & $\begin{array}{l}\text { Leadership skills, interactive communication, analytical skills, decision- } \\
\text { making skills, ability to apply technology, Global Awareness, Ethics, } \\
\text { Planning, Autonomy. }\end{array}$ \\
\hline Lê and Đỗ [7] & Employer & Ability to solve situation work, ability to meet work, Adaptability and things. \\
\hline Lan and Hiển [5] & Employer & $\begin{array}{l}\text { Group basic skills, value-added groups, group technical skills, cognitive skills } \\
\text { groups, group social skills and behaviour household with for future leaders }\end{array}$ \\
\hline $\begin{array}{c}\text { Chonko and Caballero } \\
{[6]}\end{array}$ & Employer & $\begin{array}{l}\text { Critical thinking, ability to work professional, media communication, cultural } \\
\text { awareness multinational, technology application capabilities, Proficient } \\
\text { professional fields. }\end{array}$ \\
\hline Bridges, et al. [3] & $\begin{array}{l}\text { Students } \\
\text { practice, } \\
\text { lecturers }\end{array}$ & $\begin{array}{l}\text { Communication, presentations, conflict resolution, office work, Corporate } \\
\text { Culture, Business Communication, Organizational Change, Health, } \\
\text { Understanding the diversity of employees. }\end{array}$ \\
\hline
\end{tabular}


Based on literature reviews, the authors propose a research model with Job performance including professional skills, social skills, awareness, knowledge and reliability. Moreover, Job performance factor reflects the beliefs in work which is the criterion for employees to estimate and decide the attitude of employers to graduates.

Attitude is an important factor affecting the intention of employers to behave through the process of interaction with candidates. The attitude of studying and systematising theory as well as build a scale in research of Fishbein [9]. The theory of reason action (TRA) explains one's actions based on behavioural intent in which two essential factors in adjusting behavioural intent are attitude and subjective norm. Although there are some extensive studies on the usability of the model in different cultures, however, the results show that the attitude factor is still a significant determinant of behavioural intent, but in the context of this paper is the intention to enrol labour. The casual attitude is one of the major determinants in explaining consumer behaviour. Attitude is defined as a psychological trend that is revealed through the evaluation of a specific entity with several levels such as: delicious - not good, likedislike, satisfied - dissatisfied and polarised good-bad [10]. In the logical theory of action model, attitudes are influenced by belief groups. Factors showing the competency of the candidate in the job as well as by the working environment show the employers' confidence in the job candidates. From a theoretical basis and expert discussion, the study formed a research model with hypotheses:

H1: Job performance of graduates have a positive influence on the attitude of employers.

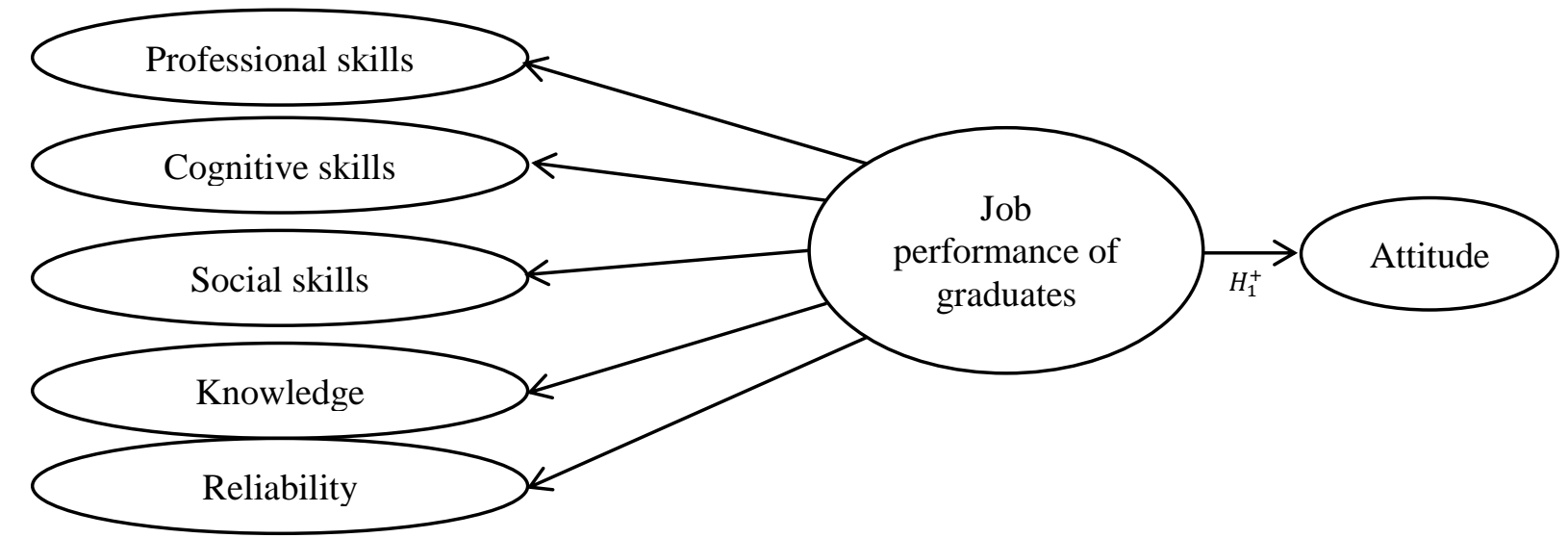

Figure 1. The conceptual model

\section{RESEARCH METHODS AND ANALYSIS OF RESULTS}

\subsection{Developing measurement scale}

Research determined the observed variables to independent and dependent factors inherited from the previous research and development through interviews of 6 businesses in different industries ( 2 division director and four business directors). After conducting a group discussion, there are four experts to formulate a scale of factors related to the model including 64 observed variables. Then, simplified to 31 observable variables by the preliminary survey to build the final survey questionnaire. Unsuitable observed variables may be eliminated in the scale test. Describe the observed variables and definitions as well as the basis of the observed variables in Table 2 .

\subsection{Data collection and sampling}

The study was conducted through two steps (1) preliminary study and (2) formal research. Preliminary studies were conducted through qualitative research methods with engineering group discussions and interview experts to provide levels of exploration, additional calibration and measurement scales. Group discussion techniques used in qualitative research and direct interview techniques were used for preliminary research by quantitative with a sample size of $n=30$. Formal research is quantitative research, an interview technique with research questionnaires is also used for this next research step with a sample size of $n=130$. 
Table 2. Questions, coding and conceptual description

\begin{tabular}{|c|c|c|}
\hline Coding & Content & Conceptual description \\
\hline KNCM1 & $\begin{array}{l}\text { Use specialised software (accounting software, personnel, or } \\
\text { customer management) to meet the job. }\end{array}$ & \multirow{5}{*}{$\begin{array}{l}\text { Professional skills: the ability } \\
\text { required to perform a specific task; } \\
\text { in other words, the professional } \\
\text { qualifications of the administrator. } \\
\text { [11] }\end{array}$} \\
\hline KNCM2 & $\begin{array}{l}\text { Quickly acquire new specialised software (accounting software, } \\
\text { human resources, or customer management) }\end{array}$ & \\
\hline KNCM4 & $\begin{array}{l}\text { Know how to apply specialised knowledge to practical work } \\
\text { requirements }(*) \text { flexibly }\end{array}$ & \\
\hline KNCM5 & Proficient use office information (word, excel, powerpoint). $\left(^{*}\right)$ & \\
\hline KNCM6 & Demonstrate professional skills. $(*)$ & \\
\hline KNXH1 & $\begin{array}{l}\text { Demonstrate the attitude of complying with the regulations of } \\
\text { the enterprise }(*)\end{array}$ & \multirow{5}{*}{$\begin{array}{l}\text { Social skills: a set of skills that } \\
\text { allow us to communicate, interact } \\
\text { and integrate, adapt to society. [12] }\end{array}$} \\
\hline KNXH2 & $\begin{array}{l}\text { Demonstrate the ability to master emotions to solve problems, } \\
\text { conflict with colleagues }\end{array}$ & \\
\hline KNXH3 & Easily adapt to changes in the work environment & \\
\hline KNXH4 & Able to withstand work pressure $(*)$ & \\
\hline KNXH5 & $\begin{array}{l}\text { Capable of presenting short and scientific problems and easy to } \\
\text { understand }(*)\end{array}$ & \\
\hline KT1 & Can know the structure and motto of operation of the business & \multirow{5}{*}{$\begin{array}{l}\text { Knowledge: is understood as the } \\
\text { ability to collect data, the ability to } \\
\text { understand problems } \\
\text { (comprehension), the ability to } \\
\text { apply, the ability to analyse, the } \\
\text { ability to synthesise (synthesis), } \\
\text { evaluation capability. [13] }\end{array}$} \\
\hline KT2 & Understand specialised laws $(*)$ & \\
\hline KT3 & $\begin{array}{l}\text { Capable of understanding and analysing with a clear and } \\
\text { systematic basis about competitors' activities }\end{array}$ & \\
\hline KT4 & $\begin{array}{l}\text { Understand the current economic situation in and out of } \\
\text { business }\end{array}$ & \\
\hline KT5 & Understand the culture of the business $(*)$ & \\
\hline TC1 & Expression of a desire to be attached to the business $(*)$ & \multirow{6}{*}{$\begin{array}{l}\text { Reliability: reflects the peace of } \\
\text { mind of employers when recruiting } \\
\text { working attitudes and } \\
\text { progression. (developed by the } \\
\text { study) }\end{array}$} \\
\hline TC2 & Shows positive self-change and self-development & \\
\hline TC3 & Have a high sense of responsibility for the job & \\
\hline TC4 & Have a spirit of progress in work & \\
\hline TC5 & Expressing enthusiasm and commitment to work & \\
\hline TC6 & Always comply with the assigned rights and responsibilities & \\
\hline KNNT1 & $\begin{array}{l}\text { Potential candidates analysing, interpreting, persuading and } \\
\text { protecting views }(*)\end{array}$ & \multirow{5}{*}{$\begin{array}{l}\text { Cognitive skills: Qualities and } \\
\text { behaviours show the attitude of } \\
\text { individuals to work and motivation, } \\
\text { as well as the qualities needed to } \\
\text { take good jobs [14] }\end{array}$} \\
\hline KNNT2 & Applicants comply with laws when performing work & \\
\hline KNNT3 & Candidates can discuss and negotiate scientifically $(*)$ & \\
\hline KNNT4 & Candidates learn before the rules and regulations of enterprises & \\
\hline KNNT5 & $\begin{array}{l}\text { Candidates comply with professional ethics (gathering } \\
\text { information, social rules) }\end{array}$ & \\
\hline
\end{tabular}

(*) The observed variables have been deleted 
Non-sampling method selection probabilities are used for this study. Through 130 interview questionnaires released, 118 valid and useful questionnaires were recovered, reaching $90.7 \%$. Thus, a sample is taken into analysis with the size of $n=118$ with descriptive statistics of the research sample.

\subsection{Sample description}

All questions are processed by statistical software such as SPSS and AMOS. All participants are working in business in Ho Chi Minh City. Among 118 respondents, three-fifths are women (69), and twofifths are men (49). Forage structure, 25-30 years old accounted for 58.5 per cent of respondents. The education level of respondents, most of them graduated from university with a rate of 88.1 per cent. The number of years working for respondents mostly over two years accounted for 69.5 per cent

\subsection{Analyse results}

The Cronbach Alpha reliability coefficient evaluates the research concept component scales and continues to be tested for convergent and discriminant values through factor analysis (EFA). We first conduct a factor analysis to demonstrate the value of the scale. The main component analysis method (PCA) combined with Varimax rotation has been used to analyse factors, resulting in factors including employer attitude, reliability, knowledge, cognitive skills, professional skills, social skills and knowledge. The observed variables that do not meet the required index (factor loading factor $<0.5$ ) have removed. The study then conducted a test of Cronbach alpha coefficients to test reliability. The results are shown in (Table 3 ) that are greater than 0.7 , thereby confirming the assurance of internal consistency. The results show that the components of the scale of attitude employers meet criteria about reliability, convergent values, and discriminant values. The results of EFA have drawn six factors at the Eigenvalue stop point of 1,065 with a total variance of $72,817 \%$. Test factor (Kaiser - Meyer - Olkin measure of sampling adequacy) $\mathrm{KMO}=0.817$, Chi-Square of Barker's test $=1062.089$ and $\mathrm{df}=171$ with sig $=$ 0.000 . The results show that the concept of factors in the study achieves reliability and convergent values as well as differentiated values, and qualifies to continue with confirmatory factor analysis step (CFA).

Table 3. Analysis of factors EFA and Cronbach's Alpha

\begin{tabular}{|c|c|c|c|c|c|c|c|}
\hline \multirow{2}{*}{ Observed variables } & \multicolumn{6}{|c|}{ Factors } & \multirow{2}{*}{$\begin{array}{c}\text { Cronbach's } \\
\text { Alpha }\end{array}$} \\
\hline & TDF & TCF & KTF & KNNTF & KNXHF & KNCMF & \\
\hline TD3 & .877 & .283 & .145 & -1032 & .034 & .024 & \multirow{4}{*}{0.901} \\
\hline TD1 & .849 & .052 & .029 & .205 & .198 & -009 & \\
\hline TD2 & .823 & .128 & -.017 & .044 & .141 & .173 & \\
\hline TD4 & .821 & .250 & .146 & -077 & .118 & (079 & \\
\hline TC4 & .120 & .789 & .018 & .109 & .183 & .141 & \multirow{5}{*}{0831} \\
\hline TC3 & .089 & .761 & .010 & .115 & .243 & .250 & \\
\hline TC5 & .337 & .717 & .106 & .069 & .062 & .156 & \\
\hline $\mathrm{TC} 2$ & .122 & .690 & .203 & .149 & .140 & -.162 & \\
\hline TC6 & .203 & .661 & .156 & .205 & -.244 & .081 & \\
\hline KT4 & .095 & .093 & .863 & -005 & .000 & .147 & \multirow{3}{*}{0.793} \\
\hline KT3 & .079 & .113 & .840 & .142 & .180 & .121 & \\
\hline KT1 & .077 & .142 &.$\overline{.626}$ & .138 & .347 & .194 & \\
\hline KNNT5 & .010 & .121 & .026 & .809 & .276 & .185 & \multirow{3}{*}{0.700} \\
\hline KNNT4 & .128 & .154 & .050 & $\underline{798}$ & .161 & .095 & \\
\hline KNNT2 & -062 & .320 & .290 & .630 & -.267 & .031 & \\
\hline KNCM2 & .240 & .101 & .212 & .155 & .754 & .057 & \multirow{2}{*}{0.755} \\
\hline KNCM1 & .188 & .191 & .162 & .103 &.$\overline{738}$ & .123 & \\
\hline KNXH3 & .161 & .192 & .204 & .052 & .157 & .831 & \multirow{2}{*}{0.708} \\
\hline KNXH2 & .058 & .099 & .211 & .237 & .034 & .826 & \\
\hline
\end{tabular}

The research model is tested through SEM structure equation with AMOS software. This study uses two approaches as suggested by Anderson [15]. First, to evaluate the measurement quality of the measurement model measurement scale, also known as the CFA test phase, then the study conducted hypothesis test through the method of testing SEM structure equation [16]. 
Results after re-running CFA, CMIN / $\mathrm{df}=1.390$; RMSEA $=0.058$, CFI $=0.941$; with $\mathrm{p}=$ 0.000 ; degrees of freedom $\mathrm{Df}=146$; TLI $=0.931$ from this result shows the model of ability to meet business requirement and employers' attitude. The scales of components are unidirectional when there is no correlation between the errors of the observed variables [17].

Correlation coefficients between the component scale concepts with a standard deviation are smaller than 1 and statistically significant. Thus, scales of conceptual knowledge, reliability, cognitive skills and professional skills, and social skills meet the discrimination validity. The standardised weights between component scales are larger than 0.5 , statistically significant with $p=0.000$, so observable variables to measure five components of the scale attitude of employers meet the convergence validity. (Table 4)

Table 4. Composite Reliability and AVE

\begin{tabular}{|c|c|c|c|c|}
\hline Factor & Encode & $\begin{array}{l}\text { Standardised factor } \\
\text { load factor }\end{array}$ & $\mathbf{C R}$ & AVE \\
\hline Attitude & $\begin{array}{l}\text { TD1 } \\
\text { TD2 } \\
\text { TD3 } \\
\text { TD4 }\end{array}$ & $\begin{array}{l}0.776 \\
0.763 \\
0.928 \\
0865\end{array}$ & 0.902 & 0.762 \\
\hline Reliability & $\begin{array}{l}\text { TC6 } \\
\text { TC5 } \\
\text { TC4 } \\
\text { TC3 } \\
\text { TC2 }\end{array}$ & $\begin{array}{l}0.612 \\
0.778 \\
0.758 \\
0.766 \\
0.622\end{array}$ & 0835 & 0.648 \\
\hline Knowledge & $\begin{array}{l}\text { KT3 } \\
\text { KT4 } \\
\text { KT1 }\end{array}$ & $\begin{array}{l}0.872 \\
0.735 \\
0.663\end{array}$ & 0.804 & 0.690 \\
\hline Cognitive skills & $\begin{array}{l}\text { KNNT2 } \\
\text { KNNT5 } \\
\text { KNNT4 }\end{array}$ & $\begin{array}{c}0.515 \\
0820 \\
0.719\end{array}$ & 0.732 & 0.632 \\
\hline Social skills & $\begin{array}{l}\text { KNXH3 } \\
\text { KNXH2 }\end{array}$ & $\begin{array}{l}0829 \\
0.765\end{array}$ & 0.777 & 0.725 \\
\hline Professional skills & $\begin{array}{l}\text { KNCM2 } \\
\text { KNCM1 }\end{array}$ & $\begin{array}{l}0.761 \\
0.726\end{array}$ & 0.712 & 0.676 \\
\hline
\end{tabular}

\subsection{Confirmatory Factor Analysis (CFA)}

The critical model has model fit results with $\mathrm{CMIN} / \mathrm{df}=1.390$ indicators; RMSEA $=0.058, \mathrm{CFI}=$ 0.941 ; with $\mathrm{p}=0.000$; degrees of freedom $\mathrm{Df}=146$; $\mathrm{TLI}=0.931$. This result shows that the model is consistent with research data, confirming the unidimensional of the concepts in the study. The weights of the employers' attitude scale to meet the requirement $>0.5$ show that the attitude scale in the model reaches convergent validity [15]. The results of the CFA analysis show that the relationship between research concepts is different from 1, so the scale of concepts perceives the ability to respond, and attitudes are reaching the discriminant validity.

Next step, a single factor structure composed of all five components was also analysed in order to assess the unidimensionality of Job performance. However, the result showed that the single factor structure provided a much poorer fit, indicating that the perceived quality is not unidimensional. The proposed hierarchical structure of job performance (Figure 1), suggests that the unidimensional nature of job performance may be apprehended through a second-order latent variable. Support for a second-order latent variable was also found in the correlations among the skills, knowledge and reliability factors. The job performance would be a unidimensional construct having several sub-components which including Cognitive skills, social skills, professional skills, knowledge and reliability. This reasoning led us to conduct an additional analysis that is discussed with the assessment of the research model.

\subsection{Model fit}

The estimated results of the research model are presented in (see Figure 2). There are two research concepts in that model that are perceived as job performance and attitudes towards graduates. The 
theoretical model has 150 degrees of freedom (see Figure 2), square value $=205.889$, with $\mathrm{p}=0.000$ other criteria all meet requirements: $\mathrm{CMIN} / \mathrm{Df}=1.373$; $\mathrm{RMSEA}=0.056, \mathrm{CFI}=0.942$ and $\mathrm{TLI}=$ 0.934. Thus, based on the above indicators, it can be concluded that this model is fit for research data

The remaining parameters estimate the standardised estimation results of the main parameters. This result shows that these relationships are statistically significant $\mathrm{P}<5 \%$. Also, it also gives us the conclusion that the scales of concepts in the research model have a theoretical relevance value because "Each measurement is related to other measures based on expected theory" [18]

The estimation results by ML in the analysis of linear structure model show that the relationship between the components of the perception of job performance and the concept of attitudes are significant $\mathrm{p}=0.000$, see (Figure 2: Critical model of the study). In other words, to the hypothesis that the ability to respond positively affects attitudes, beta $=0.56$ results, $\mathrm{p}<0.001$ confirm the hypothesis $\mathrm{H} 1$ was accepted.

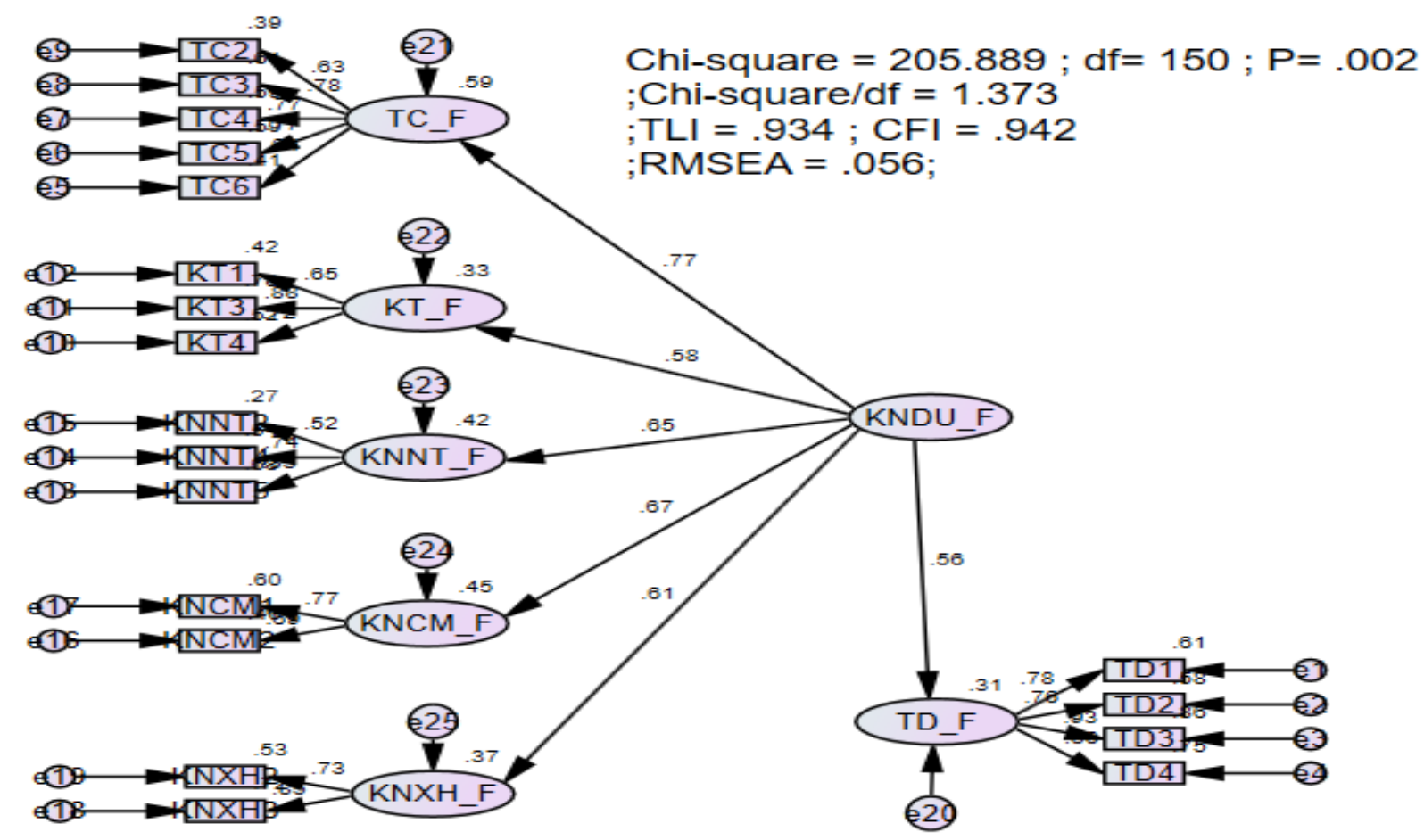

Figure 2. Critical model of the study

The hypothesised relationship was tested by path analysis using structural modelling. In hypothesis $\mathrm{H} 1$, we investigate the influence of job performance on the employer's attitude. As expected, job performance (path coefficient $=0.317$ ) had a positive effect on privacy risk beliefs. The detail of the primary hypothesis testing results is shown in Table 5.

Table 5: The result of the hypothesis test

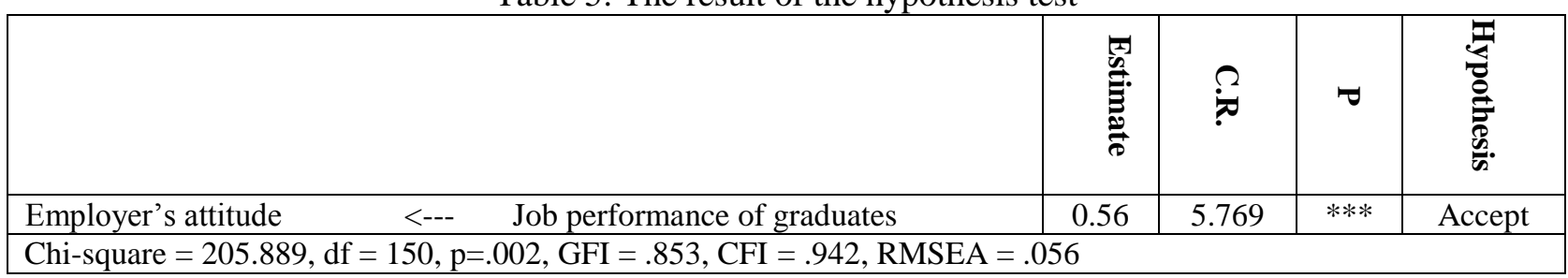

\section{DISCUSSION}

In the study, it was mentioned in theory that many authors set up a measurement scale to serve as a basis for measuring and assessing job performance under employer lens, but most studies focused on and the perception of the student or lecturer and ignore the interest of the employer. The study of Lan and 
Hiển [5] defines the measurement scale for students' ability under the perception that more than 700 businesses value research very well. However, research focuses only on the students of the technology sector and not caring about the attitude of employers.

Moreover, these studies also do not focus on testing consistency and rigour of scale to measure the ability to meet the task requirement of graduates. Therefore, this study contributes a part in building the scale and results with five main components reflecting the ability to meet the job of graduates including knowledge, expressing confidence and skills. Besides conducting the study also tested model the relationship between the ability to adapt the work and attitude of employers. Attitude is a conceptualised abstract and entirely defined by Fishbein [9]. So far, the attitude is an essential factor affecting behaviour such as the intention to recruit graduates, intending to introduce information about the students of a university, and create a link to the university.

For research, it helps to understand better the components of the ability to get the job, thereby supporting the training institution to measure and evaluate the annually about the university level of satisfying the practical requirement of the student. As for managerial, research contributes to introduce criteria for businesses to assess the recruitment of interns or new graduates. The results of the measurement models show that after adding and adjusting, all scales achieve the reliability and the content value of unidirectional value, the convergence value, and the practical value.

\section{LIMITATIONS OF RESEARCH AND FUTURE RESEARCH DIRECTIONS}

The limitation of this study only focus on a number of businesses that allow the authors to approach the survey interviews, so that the ability to generalize the results of the study will be higher if implemented at a broader and more multidisciplinary to be able to compare and build a scale system for component concepts of perceiving responsiveness to the attitude.

Second, the primary objective of the study is to build a scale of components for the new job applicants' job ability. Hence, the theoretical model considers only one causal factor that is the perceived ability to meet the impact of factors resulting in attitude. There may be other factors that impact on the attitude of the recruiter on students such as social impact, specific industries or interests of the employer. The author gives these factors for further research shortly.

\section{REFERENCE}

[1] (2015). Newsletter for Vietnam's labor market update. Available:

http://www.molisa.gov.vn/Images/FileAnPham/fileanpham201587150321.pdf

[2] S. J. Motowildo, Borman, W. C., \& Schmit, M. J., "A theory of individual differences in task and contextual performance," Human performance, vol. 10, no. 2, p. 12, 1997.

[3] M. Bridges, S. Moochhala, J. Barbour, and C. Kelly, "Influence of diabetes on peripheral bone mineral density in men: a controlled study," Acta diabetologica, vol. 42, no. 2, pp. 82-86, 2005.

[4] P. T. L. Hương and T. T. Khải, "Nhận thức kỹ năng nghề nghiệp của sinh viên chuyên ngành quản trị marketing tại Trường Đại học Kinh tế Đà Nẵng," 2010.

[5] N. H. Lan and N. M. Hiển, "Đánh giá của người sử dụng lao động về chất lượng đào tạo đại học: Một nghiên cứu đối với nhóm ngành kĩ thuật-công nghệ," VNU Journal of Science: Education Research, vol. 31, no. 2, 2015.

[6] L. B. Chonko and M. J. Caballero, "Marketing madness, or how marketing departments think they're in two places at once when they're not anywhere at all (according to some)," Journal of Marketing Education, vol. 13, no. 1, pp. 14-25, 1991. 
[7] C. L. Lê and Đ. T. Đỗ, "Đánh giá mức độ đáp ứng công việc của sinh viên tốt nghiệp (nghiên cứu khối ngành kinh tế tại trường Đại học Sài Gòn): Báo cáo tổng kết đề tài nghiên cứu khoa học cấp trường: Mã số: CS201444," 2016.

[8] P. T. L. Huong and T. T. Khai, "Nhận thức Kĩ năng nghề nghiệp của sinh viên chuyên ngành quản trị marketing tại Trường Đại học Kinh tế Đà Nẵng," Tạp chí khoa học công nghệ - Đại học kinh tế Đà Nã̃ng, no. $5,2010$.

[9] H. D. Fishbein, "Evolution, development, and children's learning," 1976.

[10] A. Eagly and S. Chaiken, "The psychology of attitudes Harcourt Brace Jovanovich Fort Worth," 1993.

[11] R. L. Katz, "Skills of an effective administrator," Harvard business review, vol. 33, no. 1, pp. 33-42, 1955.

[12] D. Goleman, Het brein en emotionele intelligentie. Business Contact, 2013.

[13] B. S. Bloom, "Taxonomy of educational objectives. Vol. 1: Cognitive domain," New York: McKay, pp. 20-24, 1956.

[14] A. J. Harrow, A taxonomy of the psychomotor domain. D. McKay Company, 1972.

[15] J. Anderson, \& Gerbing, D. W., "Structural Equation Modeling in Practice: A Review and Recommended Two-Step Approach.," Psychological Bulletin, vol. 103, no. 3, p. 12, 1988.

[16] K. G. Jöreskog, \& Sörbom, D., "LISREL 8: Structural equation modeling with the SIMPLIS command language. ," Chicago, IL, US: Scientific Software International; Hillsdale, NJ, US: Lawrence Erlbaum Associates, Inc., 1993.

[17] J.-B. E. Steenkamp and H. C. van Trijp, "Quality guidance: A consumer-based approach to food quality improvement using partial least squares," European Review of Agricultural Economics, vol. 23, no. 2, pp. 195215, 1996.

[18] G. A. Churchill and D. Iacobucci, Marketing research: methodological foundations. Dryden Press New York, 2006.

Received on February $1^{\text {st }}, 2019$

Accepted on March 25 $5^{\text {th }}, 2019$ 